\title{
Evolutionary changes of weed competitive traits in winter wheat composite cross populations in organic and conventional farming systems
}

\author{
N.O. Bertholdsson ${ }^{\mathrm{a}, *}$, O. Weedon ${ }^{\mathrm{b}}$, S. Brumlop ${ }^{\mathrm{b}}$, M.R. Finckh ${ }^{\mathrm{b}}$ \\ a Dept. of Plant Breeding, Swedish University of Agricultural Sciences, P.O. Box 101, SE-230 53 Alnarp, Sweden \\ ${ }^{\mathrm{b}}$ Department of Ecological Plant Protection, University of Kassel, Nordbahnhofstr. 1a, Witzenhausen, D-37213, Germany
}

\section{A R T I C L E I N F O}

\section{Article history:}

Received 29 April 2015

Received in revised form 30 April 2016

Accepted 6 May 2016

\section{Keywords:}

Early vigour

Root growth

Shoot growth

Allelopathic activity

Hydroponics

Wheat

Organic

CCP

Evolution

Shannon-Weaver diversity index

\begin{abstract}
A B S T R A C T
Seedling root and shoot growth in hydroponics and allelopathic activity using a bioassay have been studied in very diverse populations of winter wheat grown under either organic or conventional conditions for a number of generations and subjected only to natural selection. The study was conducted on seeds from generation $6\left(\mathrm{~F}_{6}\right)$ and $11\left(\mathrm{~F}_{11}\right)$ from three composite cross populations (CCPs) produced by the Organic Research Centre in the UK. Since the $F_{5}$ the populations were maintained under organic and conventional conditions in Germany. Two parallel populations were created from each CC, resulting in a total of six organic and six conventional CCPs. The sets of parallel populations showed similar evolutionary trends indicating that the observed changes are related to differences in management rather than chance. Seedling root length and seedling root and shoot weight in the $F_{11}$ of the organically-managed CCPs were significantly greater than in the organic $\mathrm{F}_{6} \mathrm{CCPs}$. In the conventionally-managed CCPs no such differences were observed. Both organic and conventional CCPs produced for quality showed higher early root and shoot growth than those produced for yield pointing to genetic differences among population types and highlighting the importance of early vigour for NUE. There were no significant differences in the allelopathic activity of the populations and between generations. The Shannon-Weaver diversity indices were similar for the studied traits in organic and conventional CCPs and hence no major changes in diversity had occurred between $F_{6}$ to $F_{11}$. As changes in plant height were small and weed pressure in the fields low it is concluded that the observed differences are more related to NUE, rather than intra-specific competition for light or the direct effect of increased weed pressure in the organic system.
\end{abstract}

(c) 2016 Elsevier B.V. All rights reserved.

\section{Introduction}

Increasingly uncertain environmental conditions require crops with high adaptability to unpredictable biotic and abiotic stresses. Genetically uniform crops often cannot adequately fulfil this requirement (Finckh, 2008; Döring et al., 2011). Biotic stresses such as pest and disease pressure can often be better managed through the use of genetic diversity. Cropping systems that are able to achieve this diversity include mixed cropping systems, multilines, variety mixtures, agroforestry systems, polycultures and genetically diverse populations produced under dynamic management such as composite cross populations (CCP) (Finckh and Wolfe,

\footnotetext{
* Corresponding author.

E-mail address: nils-ove.bertholdsson@slu.se (N.O. Bertholdsson).
}

2015; Altieri, 1999; Finckh, 2008; Döring et al., 2012; Dawson and Goldringer, 2012).

The term "evolutionary breeding", first used by Suneson (1956), describes the creation of genetically diverse populations of single crops undergoing both artificial and natural selection under different environmental conditions, but that have the added advantage of carefully selected parents for traits such as high yield and quality combined in a composite cross scheme. A well-known CCP was produced as early as the 1920's through the paired crossing of 28 barley varieties in all possible combinations (barley composite cross II) (Harlan and Martini, 1929; Muona et al., 1982). Since then, CCPs, as mentioned by Phillips and Wolfe (2005), have been made for barley (Hordeum vulgare (L.)), wheat (Triticum aestivum (L.)), oats (Avena sativa (L.)) and Phaseolus beans, although composite cross breeding for barley has been the most successful (Finckh, 2008).

Evolutionary breeding is an important tool that can be used in order to produce genetically diverse crop populations that are bet- 
ter able to adapt to changing biotic and abiotic conditions. This breeding strategy fulfils a number of goals that in light of the negative consequences of agriculture based on genetically uniform crops should be promoted and encouraged. Dynamic management of genetic resources, achieved through the cultivation of genetically diverse populations such as CCPs, subjected to different environments and selective pressures, provides an excellent complementary tool with which to conserve the genetic diversity of agricultural crops (Paillard et al., 2000; Goldringer et al., 2001, 2006; Porcher et al., 2004; Phillips and Wolfe, 2005; Döring et al., 2011). In addition, CCPs are widely used as a resource for selection (Clark et al., 2006; Jackson, 2011; Enjalbert et al., 2011; Goldringer et al., 2001, 2006; Döring et al., 2015).

Dynamic management ensures that genetic conservation is not "static" and that the crop species are able to maintain genetic variability within and between them (Brumlop et al., 2013). It ensures also that the populations are able to adapt and evolve to changing selective pressures in different environments and provides enough genetic diversity so that advantageous genetic combinations can arise, including novel and beneficial alleles through mutation and migration (Paillard et al., 2000; Goldringer et al., 2001, 2006; Porcher et al., 2004; Phillips and Wolfe, 2005; Stange et al., 2006; Döring et al., 2011). However, the need to improve baking quality characteristics and protein content in genetically diverse populations is essential in order to promote the wider use of CC populations in agriculture. Also, challenges to the adoption of diverse populations lie not only in farmer and consumer acceptance, but also in legislative and commercial uncertainties.

Nitrogen use efficiency (NUE), i.e. the grain dry matter yield divided by the supply of available nitrogen from the soil and fertilizer (Moll et al., 1982; Bingham et al. 2012) and weed competitive ability (WCA) are two characteristics that are of great importance for organic cereal production (Eisele and Köpke, 1997; Hoad et al., 2012; Arterburn et al., 2012; Costanzo and Bàrberi, 2014). In addition, early vigour of roots and shoots, as well as allelopathic activity, are important for WCA (Huel and Huel, 1996; Bertholdsson, 2005, 2011). Increasing evidence has shown that allelochemicals exuded from roots or volatiles from leaves may reduce weed growth and weed competition accordingly (Worthington and Reberg-Horton, 2013).

In diverse populations like CCPs, genotypes with early root and shoot vigour should have an advantage over non-vigorous types, as do taller genotypes. In the CCPs grown in the UK dwarfing alleles for height were reduced after 11 generations of natural selection and there were no differences found between the CCPs grown either organically or conventionally suggesting that the main reason for the natural selection of taller genotypes is competition for light (Knapp et al., 2013). Other alleles and genes introduced through breeding such as $1 \mathrm{R}$ from rye were also reduced over time, as were mutant alleles in favour of a selection for wild-type alleles. It is more difficult to hypothesize how allelopathic properties are affected by natural selection. In barley, most of the studied Nordic landraces showed higher allelopathic activity towards perennial ryegrass (Lolium perenne (L.)) than more recent cultivars (Bertholdsson, 2004); while spring wheat landraces showed low allelopathic activity (Bertholdsson, 2007).

In 2001, three wheat CCPs were created by the John Innes Centre (Norwich, UK) in co-operation with the Elm Farm Research Centre (Newbury, UK) (Wolfe et al., 2006). In 2005, progenies of the $F_{5}$ of these original three populations were received by the University of Kassel. In Germany, these populations have been maintained in two independent conventional and two independent organic sets. The two differing agricultural systems allow for the comparison of the populations for specific adaptation characteristics/traits that have developed due to differing agricultural management. The aim is to determine if specific adaptation characteristics of special inter- est in organic production systems will emerge and as such may be identified as useful breeding traits for organic production.

The present study focusses on the question of changes for traits of early vigour and allelopathy occurring in CCPs subjected to natural selection in organic and conventional systems at Kassel University from generation $F_{6}$ to $F_{11}$, and whether these changes can be related to the agricultural system the populations were subjected to. Seeds of the three CCPs created for high yield, high quality or a mixture of both, were assessed in a hydroponic system for seedling growth and with a bioassay for allelopathic activity. Changes in plant height and ear length and their diversity in the field were also analysed.

\section{Materials and methods}

\subsection{Plant material}

The three wheat (Triticum aestivum L.) composite cross populations used originated at the John Innes Centre (Norwich, UK), through the half-diallel crossing of twenty European wheat varieties, in order to create three separate populations that have been described in detail elsewhere (Wolfe et al., 2006; Döring et al., 2015). Briefly, the parental varieties chosen for the CC populations were varieties with either good baking quality or high yield that had performed well over the last few decades in the UK and were well known. Bezostaya is a well-known winter wheat variety bred in the former Soviet Union with excellent cold tolerance and has the characteristics of both high yield and high baking quality. The first population (YQ) is the product of crossing eleven high baking quality parents and Bezostaya with eight high yielding parents. The second population ( $\mathrm{Y}$ ) is made up of crossing eight high yielding parental varieties and Bezostaya with each other and the third population $(\mathrm{Q})$ is a crossing of the eleven parental varieties known for high baking quality and Bezostaya with each other (Wolfe et al., 2006; Döring et al., 2015).

The $\mathrm{F}_{2}-\mathrm{F}_{4}$ were grown at various sites in the UK under organic and conventional management and grains from all sites were bulked before sending them to Germany. Since the $F_{5}$, the three populations were maintained at the University of Kassel as well under organic $(\mathrm{O})$ as conventional $(\mathrm{C})$ management. In the $\mathrm{F}_{6}$, two parallel populations were created for each population (i.e. I and II), which were kept separately thereafter so that the total number of populations equals twelve (six organically- and six conventionallymanaged populations). These parallel populations are therefore separate and distinct. In this way, it is possible to compare the I and II populations to each other and to see if they have evolved and changed within the same system, while comparing populations grown under organic and conventional conditions will allow to compare between systems. The CCPs used in this study were the $F_{6}$ (harvested 2007) and the $F_{11}$ (harvested 2012). To allow for testing of lines instead of single plants in the bioassay for allelopathic activity, 50 random seeds of both the $F_{6}$ and $F_{11}$ populations of CYQ and OYQ were multiplied in $2013 / 2014$, resulting in $50 \mathrm{~F}_{7}$ and $50 \mathrm{~F}_{12}$ breeding lines.

\subsection{Field trials}

The composite cross wheat populations were maintained at the research fields of the University of Kassel in Neu Eichenberg $\left(51^{\circ} 22^{\prime \prime} \mathrm{N}\right.$ and $9^{\circ} 54^{\prime \prime} \mathrm{E}$, average annual precipitation: $619 \mathrm{~mm}$, average annual temperature: $7.9^{\circ} \mathrm{C}$, altitude: $247 \mathrm{~m}$ above sea level) since 2005. The average precipitation for the growing seasons of $\mathrm{F}_{6}$ and $\mathrm{F}_{11}$ was $512 \mathrm{~mm}$ and $737 \mathrm{~mm}$ and mean temperatures were $8.3^{\circ} \mathrm{C}$ and $9.1^{\circ} \mathrm{C}$, respectively. The organic and conventional field were located about $500 \mathrm{~m}$ apart. The soil of the conventional field 
was generally poorer than that of the organic field; the conventional field is a sandy loam loess soil (Stagnic Luvisol) with 60 points on the German soil quality scale, which correlates to a certain degree with yield capacity. The certified organic field is a fine loamy loess soil (Haplic Luvisol) with about 80 soil points. The differences in soil quality are reflected by the fact that conventional yields were essentially the same or even lower than the organic yields in the first five years when this was recorded, usually between 4 and $6 \mathrm{t} /$ ha (Finckh et al., 2010). Apart from the removal of plants over $130 \mathrm{~cm}$, which occurred only rarely, the composite cross populations, organic and conventional, have been growing without conscious selection.

All populations were grown on plots $>100 \mathrm{~m}^{2}$ (for each population) and were bordered by $3 \mathrm{~m}$ non-wheat or themselves, i.e. a non-harvested border, in order to prevent outcrossing between the different populations. The pre-crops for the organic wheat populations were two years of a grass-clover mixture as green manure crop for provision of adequate nutrition. Row distance was generally $30 \mathrm{~cm}$ to allow for weed control through mechanical harrowing at tillering and hoeing at later stages if needed. The conventional populations were rotated yearly with grass-clover. No fungicides or insecticides were applied to allow for naturally occurring diseases and insects to exert natural selection pressure. Herbicides, either Axial ${ }^{\circledR}$ for annual grasses (pinoxaden and safener cloquintocetmexyl) or Broadway ${ }^{\circledR}$ Star for annual grasses and broad-leaved weeds (pyroxsulam and florasulam), were applied once a year in early spring as weed pressure was moderate due to the rotation with grass-clover. Mineral nitrogen fertilizer at a rate of $125 \mathrm{~kg} / \mathrm{ha}$ was applied in two split applications during the growing season ( 50 and $75 \mathrm{~kg} /$ ha at each application, respectively). At stem elongation, growth regulators were applied in 2008 and 2009, but not in 2010 or thereafter. Additional field data will not be reported, but as straw length and indirectly ear length are related to early seedling growth, some data for these two traits will also be presented here. Straw length (excl. ears) and ear length were measured before harvest on 50 and 200 randomly selected tillers per CCP in the $F_{6}$ and $\mathrm{F}_{11}$, respectively.

\subsection{Hydroponics}

A hydroponic system developed earlier for barley studies was used for the winter wheat CCPs in order to measure traits of early vigour (Bertholdsson and Kolodinska Brantestam, 2009). Seedlings were grown in containers $(25 \mathrm{~L})$ in a balanced complete nutrient solution with a phosphate buffer ( $\mathrm{pH} \mathrm{6.5)} \mathrm{(Larsson,} \mathrm{1982).} \mathrm{The}$ seeds were sown on strips of corrugated paper suspended in special frames in the hydroponic containers. The lower part of the strip was ironed to prevent the seeds from falling down. Strips of filter paper were used as wicks close to the strips of corrugated paper. After sowing, the strips were sprayed with a detergent (Lisapol, $0.5 \%$ ) and were covered with filter papers partly hanging down into the solution until the seeds germinated. The 24CCPs were randomized in each container with ten plants per CCP and repeated 8 times at high $(4 \mathrm{mM})$ and low $(2 \mathrm{mM}) \mathrm{N}$ concentration. The containers were placed in a growth chamber with $16 \mathrm{~h}$ of artificial light $\left(250 \mu \mathrm{mol} \mathrm{m}^{-2} \mathrm{~s}^{-1}\right.$ in the range $\left.400-700 \mathrm{~nm}\right)$ for two weeks at $18^{\circ} \mathrm{C}$. The nutrient solution was renewed weekly and aerated by continuous bubbling of air through the solution. At the end of the experiment, when the plants were 14 days old, the length of the longest seminal root (RootL) and the stem length up to the first leaf blade (leaf-sheath included)(ShootL) were measured on each plant, as well as the fresh weight of roots (RootW) and shoots (ShootW). Total seedling fresh weight was calculated as the sum of root and shoot weight (PlantW).

\subsection{Allelopathic bioassay}

A bioassay developed in an earlier project was used for the analysis of potential allelopathic activity (PAA) (Bertholdsson, 2004). In the case of single plant analysis, one pre-germinated wheat seed was planted in the centre of a 400-mL Phytotech tissue culture vial (bottom diameter $75 \mathrm{~mm}$ ), which was filled with $20 \mathrm{~mL}$ of $0.35 \%$ water-agar. Eight pre-germinated ryegrass seedlings cv. Helmer (receiver plants) were planted in a circle around the wheat seedling. For the analysis of lines developed from single seeds from the organic and conventional CCP, four pre-germinated wheat seedlings were planted along the wall and eight pre-germinated ryegrass seedlings were planted in a circle in the centre of the vial. The wheat and ryegrass seeds were pre-germinated on filter paper in darkness for three days at $21^{\circ} \mathrm{C}$. In the case of wheat, the seeds were placed with the seed notch facing downwards and covered by a filter paper, ensuring that the roots were horizontally adjusted and would germinate uniformly. The vials were sealed with a lid that allowed some passage of air and were placed in a growth chamber with a light/dark cycle of $16 / 8 \mathrm{~h}$ at a temperature of $21^{\circ} \mathrm{C}$ and inflorescent light of $52 \mu \mathrm{mol} \times \mathrm{m}^{-2} \mathrm{~s}^{-1}$. After seven days, the root area $\left(\mathrm{mm}^{2}\right)$ of the receiver plants was measured using an image analyser (DIAS, Delta-T Devices, Cambridge, England). Vials with only receiver plants were used as controls. PAA was calculated according to $\mathrm{PAA}=(1-\mathrm{A} 1 / \mathrm{A} 2) \times 100$ with $\mathrm{A} 1=$ receiver root area in the presence of wheat and $A 2=$ receiver root area without wheat. Fifty randomly selected $F_{6}$ and $F_{11}$ seeds of $C A$ and $O A$ were tested, as well as 50CCP lines of $C A$ and $O A\left(F_{7}\right.$ and $\left.F_{12}\right)$ in two replicates. Only seeds from the OA and CA were used in the bioassay.

\subsection{Statistical analysis}

Statgraphics Plus (Manugistics, Inc.) was used for ANOVA calculations. The hydroponic data was treated as randomized factorial block experiments with CCPs, generation and nutrient concentrations as factors with containers as blocks. Thousand grain weights (TGW) were very different among the different seed samples and TGW correlated with the early vigour traits $(r=0.47 \mathrm{~ns}, \mathrm{r}=0.42 \mathrm{~ns}$; $\mathrm{r}=74 \mathrm{P}<0.01$ and $0.75 \mathrm{P}<0.01$ for RootL, ShootL, RootW and ShootW, respectively). Therefore, co-variances with TGW were included in the ANOVA for root, shoot, and plant weight and adjusted values for the co-variance are reported for these parameters. In a second ANOVA, the means over nutrients were used with generation, system and CCP as factors. PAA data was treated as a completely randomized factorial experiment with CCPs and Generation as factors. The Shannon-Weaver Diversity Index, $\mathrm{H}$, was calculated as $\mathrm{H}=-\sum p \ln p$, where $p$ is the frequency proportion of different phenotypic classes, which were calculated by dividing the data into classes of equal length. In these calculations, the two parallel populations (I and II) were treated as replicates.

\section{Results}

\subsection{Field traits}

The mean stem length of conventional CCPs in the $F_{6}$ was $58.2 \mathrm{~cm}$ and significantly shorter than the organically-managed CCPs $(86.1 \mathrm{~cm})$, having been treated with growth regulators in that year. In the $F_{11}$ when no growth regulators had been used on the conventional CCPs the heights of the organic and conventional populations were more similar with 77.0 and $77.0 \mathrm{~cm}$, respectively. In the $F_{11}$, the $Y$ populations were shortest $(71.6 \mathrm{~cm})$ and the $Q$ populations were significantly taller $(80.6 \mathrm{~cm})(\mathrm{P}<0.05)$, with the YQ populations in between $(78.8 \mathrm{~cm})$. Most organically managed $\mathrm{F}_{6}$ populations had longer ear length $(6.5 \mathrm{~cm})$ than the conventionally 

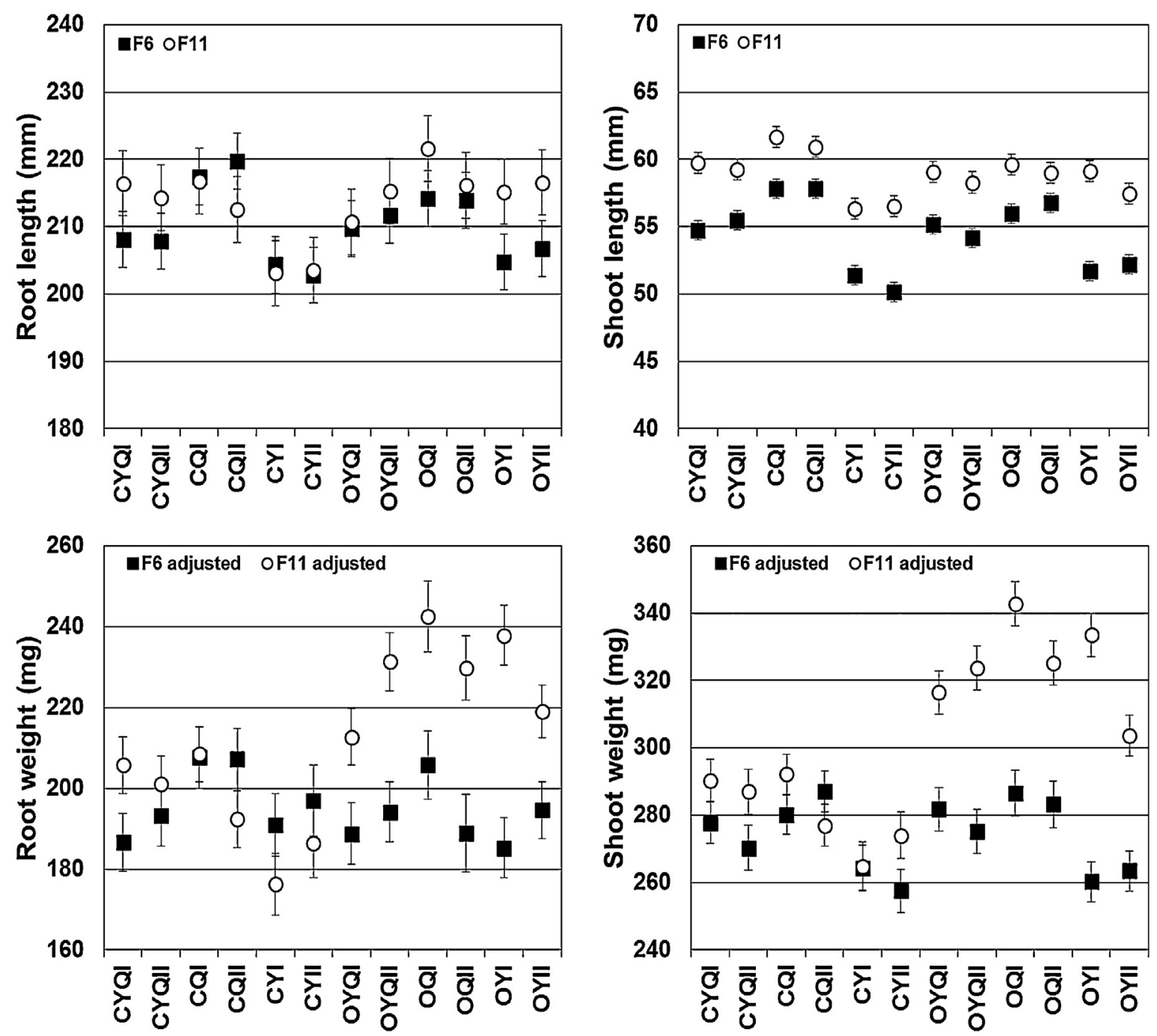

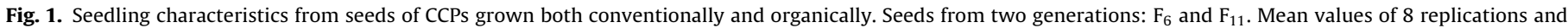
two $\mathrm{N}$-concentrations in hydroponic studies.

managed populations $(5.5 \mathrm{~cm})$. The differences were smaller in the $\mathrm{F}_{11}$. Mean ear length of the organic CCPs was $8.8 \mathrm{~cm}$ and the conventional ones $8.7 \mathrm{~cm}$. The Shannon-Weaver Diversity Index of the stems did not differ significantly for conventional and organic CCPs (Table 1). However, a significant System $\times$ Generation interaction $(\mathrm{P}<0.04)$ and the Duncan test revealed an increased diversity index for the organically-grown $F_{11}$ populations for stem length (Table 1). The diversity of the ear length was lower in the $F_{11}$ than in the $F_{6}$ for both conventionally and organically grown CCPs (Table 1 ).

\subsection{Seedling traits}

TGW of seeds from the $F_{6}$ and $F_{11}$ was higher in the organic CCPs than in conventional, and this was also true for generations $\mathrm{F}_{7}-\mathrm{F}_{9}$ (Table 2). Generally, CQ and OQ had a larger TGW than CY and OY, respectively. Since the CCPs were grown in separate fields, the differences in TGW were likely not genetic, but due to differences in soil quality. As TGW correlated with early seeding vigour as explained above, statistics for the adjusted values for the covariance of TGW are presented in the following.

Adjusted values for seedling traits of conventionally-grown CCPs were lower than non-adjusted and opposite for organicallymanaged CCPs (Fig. 1). Within system, the two parallel CCPs of YQ, $\mathrm{Q}$ and $\mathrm{Y}$, respectively, were very similar for the length or weight traits (Fig. 1). The values of the seedling traits of most CCPs were higher in the $F_{11}$ than in the $F_{6}$, and most notably in the organic CCPs for shoot weight (Fig. 1).

The seedling growth traits were studied at two nutrient $(\mathrm{N})$ concentrations. The MS values of the $\mathrm{N} \times \mathrm{CCP}$ interactions were low and without cross-overs. The significant interactions between $\mathrm{N} \times$ Generation and for Generation $\times \mathrm{CCP}$ for RootW, ShootW and PlantW indicated that changes occurred over time (data not shown). To simplify, data were analysed across $\mathrm{N}$ levels for population, generation and growing system effects (Table 3 ). The mean values of the seedling traits in the $F_{6}$ were very similar for the two systems. In contrast, in the $F_{11}$, the mean values of RootW, ShootW and PlantW were higher in organically managed CCPs than in the conventionally managed while shoot length had increased for all populations (Table 4, Fig. 1). The mean values over system of the $Y$ populations were lower than for the Q populations (Table 4). Within system, in the F6 all studied seedling traits were shortest in $\mathrm{CY}$ and OY and longest in CQ and OQ. By the F11, the conventionally maintained CY populations had not changed in root length compared to the F6. In contrast, the organic OY had by then significantly longer roots and weight characteristisc than the CY populations (Table 4 , Fig. 1). Changes in the $\mathrm{Q}$ and YQ populations were with respect to system were much less pronounced. 
Table 1

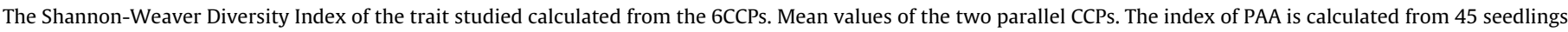

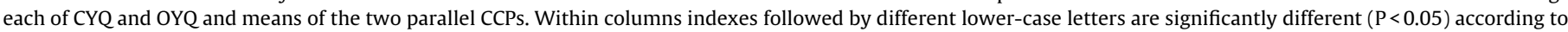
the Duncan test.

\begin{tabular}{|c|c|c|c|c|c|c|c|c|}
\hline System & Generation & Stem length & Ear length & Root length & Shoot length & Root weight & Shoot weight & $\mathrm{PAA}^{\mathrm{a}}$ \\
\hline Conventional & F6 & $2.44 \mathrm{ab}$ & $2.78 \mathrm{~b}$ & 1.70 & 1.81 & 1.92 & 2.08 & $1.31 \mathrm{a}$ \\
\hline Conventional & F11 & $2.38 \mathrm{ab}$ & $2.31 \mathrm{a}$ & 1.71 & 1.77 & 2.00 & 2.17 & $1.37 \mathrm{ab}$ \\
\hline Organic & F6 & $2.34 \mathrm{a}$ & $2.71 \mathrm{~b}$ & 1.70 & 1.73 & 1.93 & 2.02 & $1.54 \mathrm{~b}$ \\
\hline Organic & F11 & $2.52 \mathrm{~b}$ & $2.36 \mathrm{a}$ & 1.72 & 1.7 & 2.03 & 2.2 & $1.37 \mathrm{ab}$ \\
\hline
\end{tabular}

a PAA: potential allelopathic activity, see Section 2 for calculations.

Table 2

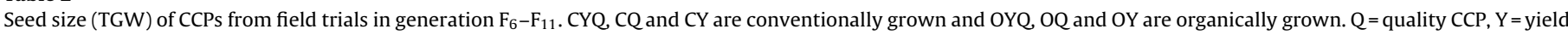

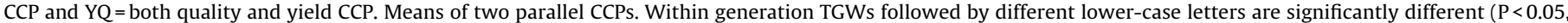
Duncan).

\begin{tabular}{|c|c|c|c|c|c|c|c|c|c|c|}
\hline Population $^{\mathrm{a}}$ & F6 & & F7 & & F8 & & F9 & & F11 & \\
\hline CYQ & 38.7 & $\mathrm{a}$ & 48.4 & $a b$ & 50.2 & $a b$ & 36.0 & $\mathrm{a}$ & 42.6 & $\mathrm{a}$ \\
\hline CQ & 40.0 & $a b$ & 50.9 & $a b$ & 50.1 & $a b$ & 36.4 & $\mathrm{a}$ & 43.0 & $\mathrm{a}$ \\
\hline $\mathrm{CY}$ & 39.3 & $\mathrm{a}$ & 46.9 & $\mathrm{a}$ & 48.7 & $\mathrm{a}$ & 33.0 & $\mathrm{a}$ & 40.4 & $\mathrm{a}$ \\
\hline OYQ & 43.6 & $\mathrm{~d}$ & 53.4 & $a b$ & 53.0 & $a b$ & 40.7 & $\mathrm{~b}$ & 47.5 & $\mathrm{~b}$ \\
\hline OQ & 44.8 & $\mathrm{e}$ & 52.6 & $a b$ & 53.0 & $a b$ & 41.8 & $\mathrm{~b}$ & 48.4 & $\mathrm{~b}$ \\
\hline OY & 41.3 & c & 55.2 & $\mathrm{~b}$ & 55.0 & $\mathrm{~b}$ & 40.8 & $\mathrm{~b}$ & 46.4 & $\mathrm{~b}$ \\
\hline
\end{tabular}

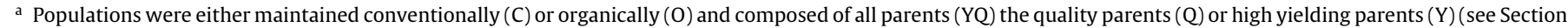
2 for more details)

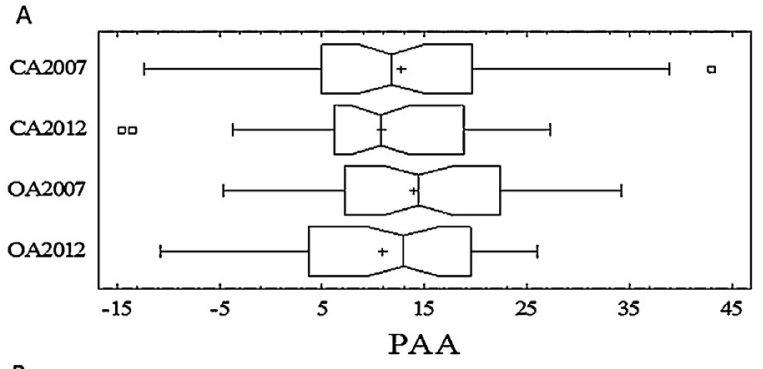

B

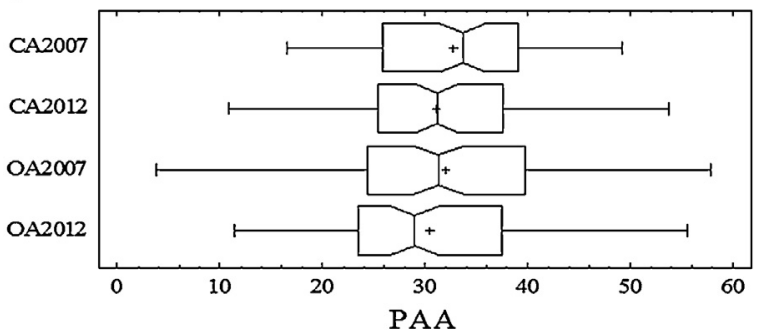

Fig. 2. Bioassay results of 50 seeds from each CCP. One wheat plant per vial (YQ), four sister wheat plants per vial (B). Ryegrass was used as the receiver plants. PAA (potential allelopathic activity) = percent reduction of the ryegrass root.

There were no significant differences in the Shannon-Weaver Diversity Indices for RootL and ShootL, between generations and systems, although there was a tendency for a higher diversity index with regards to shoot length in the CYQ population compared with the OYQ population (Table 1 ).

\subsection{Allelopathy}

No significant differences were found in the YQ populations, regardless of whether one or four seedlings were tested in the bioassay with ryegrass as receiver plants (Fig. 2A, B). However, in both CYQ and OYQ median values of PAA were slightly lower in the $F_{11}$ compared with the $F_{6}$. The Shannon-Weaver Diversity Index of PAA was higher in OYQ than CYQ in the $F_{6}$, but similar in the $F_{11}$ (Table 1).

\section{Discussion}

Within five generations of population maintenance under organic and conventional conditions, early vigour traits were significantly increased in the organically managed populations. While the parallel but separate populations behaved very similarly, management effects were not apparent after one year but after five years. In contrast, no differences among organic and conventionally managed populations could be found in allelopathic interactions.

The degree to which differences in stem and ear length in the $\mathrm{F}_{11}$ of the populations are due to evolutionary changes can only be determined by testing of the organic and conventional CCPs in a common field trial (work in progress). However, the fact that the QCCPs were generally longer than the YCCPs and that stronger changes occurred in the Y populations than the YQ or Q populations in early vigour traits points to genetic differences. The hydroponic technique used in this study showed that the QCCPs had larger root and shoot systems. Greater seedling vigour in root and shoot growth affects $\mathrm{N}$ uptake in wheat (An et al., 2006), and rooting depth of winter wheat genotypes is important for the uptake of nitrogen during stem elongation and grain filling (Ytting et al., 2014). Under limited supply of available nitrogen in early developmental phases, as common in organic farming, early shoot growth will result in higher photosynthesis, resulting in more assimilates being translocated to the roots (Pang et al., 2014; Kamiji et al., 2014). Nutrient availability is often poorer under organic conditions and nutrient mineralization from organic sources tends to be slow in spring as higher temperatures are required to begin this process compared to the direct uptake soluble mineral fertilizer (Messmer et al., 2012; Finckh and van Bruggen, 2015). Increased root assimilates increase root growth, making the uptake of $\mathrm{N}$ and other nutrients even more efficient. Increased root growth also positively affects stem length (Barraclough et al., 1991), especially if the dwarfing genes are subjected to negative selection pressure (Knapp et al., 2013). The increased plant vigour and vitality will have additional positive effects on grain yield and grain size, and as such will represent a larger part of the harvested seed for the next generation. This could therefore have been the driver for the changes in early vigour observed in the organic populations.

Stem length is often used as a measure of potential WCA in cultivars (Christensen, 1995), although early culm elongation is 
Table 3

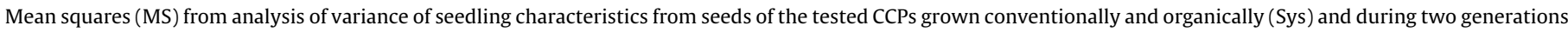
$\mathrm{F}_{6}$ and $\mathrm{F}_{11}(\mathrm{Gen})$. Analysis with mean values of two $\mathrm{N}$ concentrations and two parallel CCPs with seed size as a covariate for plant weight parameters.

\begin{tabular}{|c|c|c|c|c|c|c|}
\hline Source & Df & $\begin{array}{l}\text { RootL } \\
\text { MS }\end{array}$ & $\begin{array}{l}\text { ShootL } \\
\text { MS }\end{array}$ & $\begin{array}{l}\text { RootW } \\
\text { MS }\end{array}$ & $\begin{array}{l}\text { ShootW } \\
\text { MS }\end{array}$ & $\begin{array}{l}\text { PlantW } \\
\text { MS }\end{array}$ \\
\hline Reps & 7 & $1132^{* *}$ & $7.6^{* *}$ & $3086^{* *}$ & $1329^{* *}$ & $6426^{* *}$ \\
\hline Generation (Gen) & 1 & $317^{* *}$ & $476^{* *}$ & $7270^{* *}$ & $12367^{* *}$ & 37200 \\
\hline System (Sys) & 1 & $177^{* *}$ & 1.8 & $1366^{* *}$ & $1681^{* *}$ & $6067^{* *}$ \\
\hline Population (Pop) & 2 & $658^{* *}$ & $153^{* *}$ & $603^{* *}$ & $1396^{* *}$ & $3516^{* *}$ \\
\hline Gen $\times$ Sys & 1 & $156^{* *}$ & 0.075 & $839^{* *}$ & $9528^{* *}$ & $16005^{* *}$ \\
\hline Gen $\times$ Pop & 2 & 63 & $15.4^{* *}$ & 321 & 113 & 715 \\
\hline Sys $\times$ Pop & 2 & $173^{* *}$ & $20.9^{* *}$ & 281 & 49 & 564 \\
\hline Gen $\times$ Sys $\times$ Pop & 2 & $162^{* *}$ & 0.695 & $547^{* *}$ & $327^{*}$ & $1547^{*}$ \\
\hline Residual & 77 & 21 & 1.2 & 100 & 143 & 410 \\
\hline
\end{tabular}

${ }^{*} \mathrm{P}<0.05$.

${ }^{* *} \mathrm{P}<0.01$

most likely an influential factor negatively affecting weed growth (Bertholdsson, 2005, 2011). The hydroponic system excludes environmental effects. One complicating factor in the trial was the different seed quality and seed management history, which may have affected results. If possible, seeds with similar vitality and preferably from the same field should be used. Regarding the populations used in this study, the seeds of the organic CCPs were larger than the seeds of the conventional populations in all generations from the $F_{6}$ to $F_{11}$. The larger seed size of the organic populations should have implications for early vigour, since there is an association between early growth and seed size; whether seed size is based on genetic inheritance is not entirely clear (Aparicio et al., 2002). Silvertown (1989), however, argued that seed size heritability is considered to be low and that seed size variation tends to be a result of phenotypic plasticity, which is thought to be adaptive, especially as the result of environmental variation (Marshall et al., 1985; Vaughton and Ramsey, 1997; Lehtilä and Ehrlén, 2005). The larger seeds obtained from the organic populations reflect the higher soil quality of the organic field. Botwright et al. (2001) concluded that differences in coleoptile length were more associated with genetics than grain size or seed production.

TGW and seedling characteristics in the hydroponic system were significantly correlated. However, the statistical differences in of the co-variance analysis were almost identical to the analysis of the raw values. The effects of seed size cannot be ignored and the difference in seed size between the agricultural systems and populations should be taken into account when interpreting the results of the study. However, it appears sound to conclude that the observed differences were due to management differences changing the populations and not only due to seed size effects. Evolutionarily, however, it may be more advantageous for genotypes to produce more and smaller seeds (Döring et al., 2011). Higher TGW of the organic populations may be due to the taller plants and larger ears found in the organic populations, which may have resulted in larger seeds. In the studied populations, the correlation coefficient between TGW and stem length was $r=0.86$ and $r=0.73(P<0.05)$, in the conventional and organic CCPs, respectively.

The high genetic diversity found in CCPs gives them a general advantage over cultivars through greater possibilities for adaptation (Finckh et al., 2009; Kassie, 2014; Finckh and Wolfe, 2015). The Shannon-Weaver Diversity Index $(\mathrm{H})$ calculated for stem and ear length in the field and seedling root and shoot length in the hydroponic system showed only small and non-significant changes from the $F_{6}$ to $F_{11}$. This was also the case when comparing the populations in the two systems. One exception was $\mathrm{H}$ for ear length, which decreased from the $\mathrm{F}_{6}$ to $\mathrm{F}_{11}$ in both organic and conventional CCPs, indicating a change towards more uniform ears.

Although there were clear effects on early vigour seedling characteristics, there were no real differences with regards to allelopathy. In the bioassay, ryegrass seedlings were used as receiver plants based on the results obtained from earlier allelopathic studies (Bertholdsson, 2004). In the first round of testing for

Table 4

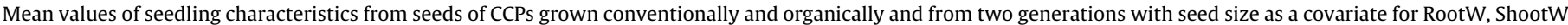

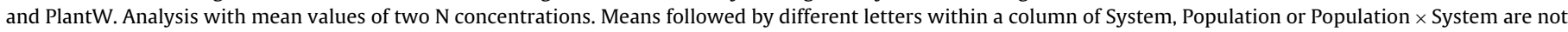
significantly different $(\mathrm{P}<0.05)$ according to the Duncan test.

\begin{tabular}{|c|c|c|c|c|c|c|c|c|c|c|}
\hline \multirow[t]{2}{*}{ Gen } & \multicolumn{2}{|c|}{ RootL (mm) } & \multicolumn{2}{|c|}{ ShootL(mm) } & \multicolumn{2}{|c|}{ RootW (mg) } & \multicolumn{2}{|c|}{ ShootW (mg) } & \multicolumn{2}{|c|}{ PlantW (mg) } \\
\hline & $\mathrm{F}_{6}$ & $\mathrm{~F}_{11}$ & $\mathrm{~F}_{6}$ & $\mathrm{~F}_{11}$ & $\mathrm{~F}_{6 \mathrm{adj}}$ & $\mathrm{F}_{11 \mathrm{adj}}$ & $F_{6 a d j}$ & $F_{11 \text { adj }}$ & $F_{6 a d j}$ & $F_{11 \text { adj }}$ \\
\hline \multicolumn{11}{|c|}{ Gen $\times$ System } \\
\hline Conv $^{\mathrm{a}}$ & $210 a$ & $211 \mathrm{a}$ & 55 & 59 & $197 b$ & $195 b$ & $273 b$ & $281 b$ & $456 b$ & $481 b$ \\
\hline Org & $210 a$ & $216 b$ & 54 & 59 & $193 b$ & $229 a$ & $275 b$ & $324 a$ & $475 b$ & $553 a$ \\
\hline \multicolumn{11}{|c|}{ Gen $\times$ Population ${ }^{\mathrm{b}}$} \\
\hline YQ & 209 & 214 & 55de & $59 \mathrm{ab}$ & 191 & 213 & 276 & 304 & 465 & 518 \\
\hline Q & 216 & 218 & $57 c d$ & $60 a$ & 202 & 218 & 284 & 309 & 488 & 529 \\
\hline $\mathrm{Y}$ & 205 & 210 & $51 \mathrm{e}$ & $57 \mathrm{bc}$ & 192 & 205 & 261 & 294 & 445 & 503 \\
\hline \multicolumn{11}{|c|}{ Gen $\times$ Population $\times$ System $^{\mathrm{b}}$} \\
\hline CYQ & 208cde & $215 a b c$ & 55 & 59 & $190 \mathrm{~cd}$ & 203abcd & $274 d$ & $289 b c$ & $454 c$ & $495 b c$ \\
\hline CQ & $219 a$ & $215 \mathrm{ab}$ & 58 & 61 & 207abcd & 200bcd & $284 d$ & $285 c d$ & $478 c$ & 490 \\
\hline $\mathrm{CY}$ & $204 \mathrm{e}$ & $203 e$ & 51 & 56 & $194 \mathrm{~cd}$ & $181 d$ & 261d & 269d & $438 \mathrm{c}$ & $458 c$ \\
\hline OYQ & 211bcde & 213abcd & 55 & 59 & $191 \mathrm{~cd}$ & $222 \mathrm{abc}$ & $278 d$ & $320 a b$ & 476 & $540 \mathrm{ab}$ \\
\hline $\mathrm{OQ}$ & 214abc & $219 a$ & 56 & 59 & 197bcd & $236 a$ & $284 \mathrm{~cd}$ & $334 a$ & $497 \mathrm{bc}$ & $569 a$ \\
\hline OY & 206de & $216 a b$ & 52 & 58 & $190 \mathrm{~cd}$ & $228 a b$ & $262 d$ & 319abc & $452 c$ & 549ab \\
\hline
\end{tabular}

a Conv: conventionally and org: organically maintained populations.

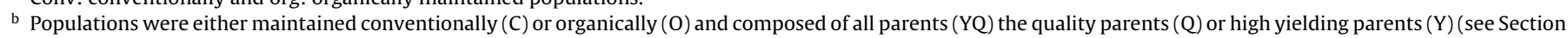
2 for more details). 
allelopathic activity single plants were tested, whereas additional testing made use of four sister plants, after multiplying 50 lines from single seeds (seeds from the $F_{7}$ and $F_{12}$ ). Both, single plants and the lines, showed similar PAA values, although the PAA value was half of that with single plants compared with four plants. In both tests, however, there was a tendency towards decreasing PAA values from the $F_{6}$ to $F_{11}$. This trend may be partly explained by the fact that releasing allelochemicals tends to be costly for the plant and therefore is not favoured by natural selection in the CCPs. As weed control was done and weed pressure was generally low in the fields where the populations were maintained there was likely no special advantage of added allelopathy. In harsher environments, however, allelopathy may help the plant to survive and may therefore be favoured during selection. Auto-toxicity may also play a role in this case (Oueslati et al., 2005).

The CCPs used in this study have also been grown in England for more than 11 generations, both under organic and conventional management. An analysis of allele frequencies in these UK populations showed that no adaptation to management could be detected in the traits that were studied (Knapp et al., 2013). However, signs of natural selection were observed common to both systems, which included a decrease in the frequency of alleles related to dwarfing, photoperiod sensitivity and the introgression of the $1 \mathrm{R}$ chromosome. Hence, the populations were shown to favour selection of the wild type alleles over the mutant alleles, which had been introduced through breeding efforts. Regardless of whether the CCPs were grown organically or conventionally, increasing height was the main genetic change that had taken place after 11 generations under natural selection in the UK, but not in the five generations in Germany reported here.

\section{Conclusions}

This is the first study documenting systems effects on the evolution of the CCPs. These were shown for important traits of early vigour and are in contrast to the findings using molecular markers by Knapp et al. (2013). Characteristics for early vigour, but not allelopathy, were improved after 5 years in organically-managed CC populations in comparison to conventionally-managed CCPs. Evolutionarily the parallel CCPs with few exceptions, demonstrated very similar behaviour, indicating that the differences are related to individual populations and management systems. These evolutionary changes towards early vigour in the organic CCPs are probably due to the combined effects of selection for higher nitrogen uptake under low-input conditions, and increased competition for light and larger seeds, rather than a direct adaptation to higher weed pressure. The use of artificial techniques like hydroponics and bioassays, as used in this study, offers an additional highly sensitive way to study early vigour and allelopathy under controlled conditions.

\section{Acknowledgements}

The Swedish Research Council for the Environment, Agricultural Sciences and Spatial Planning through the project 229-2012-1940 (COBRA) and the German Ministry of Agriculture and Nutrition, through the project $28100 E 082$ (PopZuchtDiva) and project 28120 E021 (COBRA), are acknowledged for the research funding. Ingegerd Nilsson, SLU for technical assistance.

\section{References}

Altieri, M., 1999. The ecological role of biodiversity in agroecosystems. Agric. Ecosyst. Environ.t 74, 19-31.

An, D., Su, J., Liu, Q., et al., 2006. Mapping QTLs for nitrogen uptake in relation to early growth of wheat (Triticum aestivum L.). Plant Soil 284, 73-84.
Aparicio, N., Villegas, D., Araus, J.L., Blanco, R.R., Royo, C., 2002. Seedling development and biomass as affected by seed size and morphology in durum wheat. J. Agric. Sci. 139, 143-150.

Arterburn, M., Murphy, K., Jones, S.S., 2012. Breeding for organic farming systems. In: Lammerts van Bueren, E.T., James Myers, R. (Eds.), Organic Crop Breeding. Wiley-Blackwell, pp. 163-172.

Barraclough, P.B., Weir, A.H., Khulmann, H., 1991. Factors affecting the growth and distribution of winter wheat roots under UK field conditions. In: McMichael, B.L., Persson, H. (Eds.), Development in Agricultural and Managed-Forest Ecology-Plant Roots and Their Environment. Elsevier, Amsterdam, pp. 410-417.

Bertholdsson, N.-O., Kolodinska Brantestam, A., 2009. Breeding for improved yield in Nordic barley germplasms and its effects on early vigour, straw length and harvest index. Eur. J. Agron. 30, 266-274.

Bertholdsson, N.O., 2004. Variation in allelopathic activity over 100 years of barley selection and breeding. Weed Res. 44, 78-86.

Bertholdsson, N.O., 2005. Early vigour and allelopathy-two useful traits for enhanced barley and wheat competitiveness with weeds. Weed Res. 45, 94-102.

Bertholdsson, N.O., 2007. Varietal variation in allelopathic activity in wheat and barley and possibilities to use this in breeding. Allelopathy J. 19, 193-202.

Bertholdsson, N.-O., 2011. Use of multivariate statistics to separate allelopathic and competitive factors influencing weed suppression ability in winter wheat. Weed Res. 51, 273-283.

Bingham, I.J., Karley, A.J., White, P.J., Thomas, W.T.B., Russel, J.R., 2012. Analysis of improvements in nitrogen use efficiency associated with 75 years of spring barley breeding. Eur. J. Agron. 42, 49-58.

Botwright, T.L., Rebetzke, G.J., Condon, A.G., Richards, R.A., 2001. Influence of variety: seed position and seed source on screening for coleoptile length in bread wheat (Triticum aestivum L.). Euphytica 119, 349-356.

Brumlop, S., Reichenbecher, W., Tappeser, B., Finckh, M.R., 2013. What is the SMARTest way to breed plants and increase agrobiodiversity? Euphytica 194 53-66.

Christensen, S., 1995. Weed suppression ability of spring barley varieties. Weed Res. 35, 241-249.

Clark, D., Biggerstaff, D., Cook, C., Sharp, G., 2006. New cultivars. Annu. Wheat Newslett. 52, 16-17.

Costanzo, A., Bàrberi, P., 2014. Functional agrobiodiversity and agroecosystem services in sustainable wheat production: a review. Agron. Sustainable Dev. 34, 327-348.

Döring, T., Knapp, S., Kovacs, G., Murphy, K., Wolfe, M., 2011. Evolutionary plant breeding in cereals-into a new era. Sustainability 3, 1944-1971.

Döring, T., Pautasso, M., Wolfe, M., Finckh, M.R., 2012. Pest and disease management in organic farming: implications and inspirations for plant breeding. In: Lammerts van Bueren, E., Myers, J. (Eds.), Organic Crop Breeding. Wiley-Blackwell, Oxford, pp. 39-55.

Döring, T.F., Annicchiarico, P., Clarke, S., Haigh, Z., Jones, H.E., Pearce, H., Snape, J., Zhang, J., Wolfe, M.S., 2015. Comparative analysis of performance and stability among composite cross populations: variety mixtures and pure lines of winter wheat in organic and conventional cropping systems. Field Crops Res. 183. 235-245.

Dawson, J., Goldringer, I., 2012. Pest and disease management in organic farming: implications and inspirations for plant breeding. In: Lammerts van Bueren, E. Myers, J. (Eds.), Organic Crop Breeding. Wiley-Blackwell, Oxford, pp. 77-94.

Eisele, J.A., Köpke, U., 1997. Choice of cultivars in organic farming: new criteria for winter wheat ideotypes. 2 : Weed competitiveness of morphologically different cultivars. Pflanzenbauwissenschaften 1, 84-89.

Enjalbert, J., Dawson, J., Paillard, S., Rhoné, B., Rousselle, Y., Thomas, M., Goldringer, I., 2011. Dynamic management of crop diversity: from an experimental approach to on-farm conservation. C.R. Biol. 334, 458-468.

Finckh, M., Wolfe, M., et al., 2015. Biodiversity enhancement. In: Finckh, M. (Ed.), Plant Diseases and Their Management in Organic Agriculture. APS Press, St. Paul, MN, USA, pp. 153-174 (Chapter 4.4).

Finckh, M., van Bruggen, A.H.C., et al., 2015. Organic production of annual crops. In: Finckh, M (Eds.), Plant Diseases and Their Management in Organic Agriculture. APS Press, St. Paul, MN, USA, pp. 25-32 (Chapter 2.2).

Finckh, M., Brumlop, S., Goldringer, G., Steffan, P., Wolfe, M.S., 2009. Maintenance of diversity in naturally evolving composite cross wheat populations in Europe. In: Collected Papers of the 1st IFOAM International Conference on Organic Animal and Plant Breeding. Breeding Diversity, August 25-28, pp. 145-152.

Finckh, M.R., Grosse, M., Weedon, O., Brumlop, S., 2010. Population developments from the F5 to the F9 of three wheat composite crosses under organic and conventional conditions. In: EUCARPIA 2nd Conference of the Organic and Low-Input Agriculture Section, 1-3 December 2010, Paris. INRA, Univ.Paris-Sud, CNRS, AgroParisTech, pp. 49-52.

Finckh, M., 2008. Integration of breeding and technology into diversification strategies for disease control in modern agriculture. Eur. J. Plant Pathol. 121, 399-409.

Goldringer, I., Enjalbert, J., David, J., Paillard, S., Pham, J., Brabant, P., 2001. Dynamic management of genetic resources: a 13-year experiment on wheat. In: Cooper, H., Spillane, C., Hodgkin, T. (Eds.), Broadening the Genetic Base of Crop Production. CABI, FAO, IPGRI, Wallingford, Rome.

Goldringer, I., Prouin, C., Rousset, M., Galic, N., Bonnin, I., 2006. Rapid differentiation of experimental populations of wheat for heading time in response to local climatic conditions. Ann. Bot. 98, 805-817. 
Harlan, H., Martini, M., 1929. A composite hybrid mixture. J. Am. Soc. Agron. 21 487-490.

Hoad, S.P., Bertholdsson, N.O., Neuhoff, D., Köpke, U., 2012. Approaches to breed for improved weed suppression in organically grown cereals. In: Lammerts van Bueren, E., Myers, J.R. (Eds.), Organic Crop Breeding. Wiley-Blackwell, pp. $61-72$.

Huel, D.G., Huel, P., 1996. Genotypic variation for competitive ability in spring wheat. Plant Breed. 115, 325-329.

Jackson, L., 2011. Wheat Cultivars for California. Davis: Department of Plant Sciences, University of California http://smallgrains.ucdavis.edu/cereal_files/ WhtCVDescLJ11.pdf.

Kamiji, Y., Pang, J., Milroy, S., Palta, J., 2014. Shoot biomass in wheat is the driver for nitrogen uptake under low nitrogen supply: but not under high nitrogen supply. Field Crops Res. 165, 92-98.

Kassie, M.M., 2014. Evaluation of phenotypic diversity among several generations of winter wheat composite cross populations and a modern cultivar under organic farming. Asian J. Plant. Sci. 13, 40-45.

Knapp, S., Snape, J., Döring, T.F., Wolfe, M.S., Griffiths, S., et al., 2013. Genetic analysis of evolving winter wheat populations reveals reversion to wild type. In: Döring, T., Howlett, S., Winkler, L. (Eds.), Conference: Proceedings of the International Symposium on Evolutionary Breeding in Cereals. Aston University, Birmingham (UK), Hamstead Marshall, UK, 9 p. http://orgprints. org/22440/ (accessed 21.01.13.).

Larsson, S., 1982. A simple: rapid and non-destructive screening method useful for drought resistance breeding in oats (Avena sativa L.). Z. Pflanzenzüchtg. 89, 206-221.

Lehtilä, K., Ehrlén, J., 2005. Seed size as an indicator of seed quality: a case study of Primula veris. Acta Oecol. 28, 207-212.

Marshall, D., Levin, D., Fowler, N., 1985. Plasticity in yield components in response to fruit predation and date of fruit initiation in three species of Sesbania (Leguminosae). J. Ecol. 73, 71-81.

Messmer, M., Hildermann, I., Thorup-Kristensen, K., Rengel, Z., 2012. Nutrient management in organic farming and consequences for direct and indirect selection strategies. In: Lammerts ban Bueren, E., Myers, J. (Eds.), Organic Crop Breeding. Wiley-Blackwell, Oxford.

Moll, R.H., Kamprath, E.J., Jackson, W.A., 1982. Analysis and interpretation of factors which contribute to efficiency to nitrogen utilization. Agron. J. 75, 562-564.
Muona, O., Allard, R., Webster, R., 1982. Evolution of resistance to Rhynchosporium secalis (Oud.) Davis in barley composite cross II. Theor. Appl. Genet. 61, 209-214.

Paillard, S., Goldringer, I., Enjalbert, J., Doussinault, G., de Vallavieille-Pope, C., Brabant, P., 2000. Evolution of resistance against powdery mildew in winter wheat populations conducted under dynamic management. I -Is specific seedling resistance selected? Theor. Appl. Genet. 101, 449-456.

Pang, J., Palta, J., Rebetzke, G., Milroy, S., 2014. Wheat genotypes with high early vigour accumulate more nitrogen and have higher photosynthetic nitrogen use efficiency during early growth. Funct. Plant Biol. 41, 215-222.

Phillips, S., Wolfe, M., 2005. Evolutionary breeding for low input systems. J. Agric. Sci. 143, 245-254.

Porcher, E., Gouyon, P., Lavigne, C., 2004. Dynamic management of genetic resources: maintenance of outcrossing in experimental metapopulations of a predominantly inbreeding species. Conserv. Genet. 5, 259-269.

Oueslati, O., Ben-Hammouda, M., Ghorbal, M.H., Guezzah, M., Kremer, R.J., 2005. Barley auto toxicity as influenced by varietal and seasonal variation. J. Agron. Crop Sci. 191, 249-254.

Silvertown, J., 1989. The paradox of seed size and adaptation. Trends Ecol. Evol. 4, 24-26.

Stange, K., Wolfe, M., Finckh, M., 2006. Diversity and evolutionary changes in a wheat composite cross as assessed by resistance frequencies and morphological parameters. In: Ostergaard, H., Fontaine, L. (Eds.), Proceedings of the COST SUSVAR Workshop on Cereal Crop Diversity: Implications for Production and Products. 13-14 June 2006, La Besse, France. ITAB (Institut Technique de l'Agriculture Biologique), Paris, France, pp. 71-74.

Suneson, C., 1956. An evolutionary plant breeding method. Agron. J. 48, 188-191.

Ytting, N.K., Andersen, S.B., Thorup-Kristensen, K., 2014. Using tube rhizotrons to measure variation in depth penetration rate among modern North-European winter wheat (Triticum aestivum L.) cultivars. Euphytica 199, 233-245.

Vaughton, G., Ramsey, M., 1997. Seed mass variation in the shru: Banksia spinulosa (Proteaceae): resource constraints and pollen source effects. Int. J. Plant Sci. $158,424-431$.

Wolfe, M., Hinchsliffe, K., Clarke, S., Jones, H., Haigh, Z., 2006. Evolutionary breeding of healthy wheat: from plot to farm. Aspects Appl. Biol. 79, 47-50.

Worthington, M., Reberg-Horton, C., 2013. Breeding cereal crops for enhanced weed suppression: optimizing allelopathy and competitive ability. J. Chem. Ecol. 39, 213-231. 